\title{
COMPOSIÇÃO E PROPRIEDADES DA FRAÇÃO LIPIDICA DE GRÃOS DE CAFẼS DE BEBIDAS MOLE, DURA, RIADA E RIO
}

\author{
H. Fonseca \\ L. E. GutierRez \\ A. A. Teixeira
}

\section{RESUMO}

\begin{abstract}
Vinte e oito amostras de grãos de cafe verde, pertencentes a variedade Mundo Novo e separadas em quatro tipos de bebidas (MOLE, DURA, RIADA e RIO) foram analisadas quanto ao teor e propriedades do extrato etéreo e a composição do oleo, em ácidos graxos. O teor do extrato etéreo foi maior para os cafés de melhor bebida, porém houve diferença significativa apenas para os de bebida DURA. Não se constataram diferenças significativas no teor de áci. dos graxos entre os quatro tipos de bebida. Quanto às propriedades químicas do extrato etéreo (índices de saponificação, acidez e iôdo) não houve diferença significativa. Concluiu-se que estes componentes e propriedades não podem ser utilizadas para a caracterização do tipo de bebida.
\end{abstract}

\section{INTRODUÇAO}

0 tipo da bebida de café é fator importante na comercialização do produto e a sua caracterização é feita através degustadores. Nos últimos anos tem sido intensa a pesquisa para relacionar a composição do grão com o tipo de bebida de café.

Em 1940, KRUG observou que havia uma correlação positiva entre o ataque de fungos e bactérias e as bebidas piores, responsabilizando Fusarium $\mathrm{sp}$ pelas bebidas duras, riadas e rio. GARRUTI ef al. (1962) anali-

- Entregue para publicaçáo em 27/12/1974.

* Departamento de Tecnologia Rural da HSALQ.

*** Bolsista de Aperfeiçoamento da Fundação de Amparo a Pesquisa do Estado de Sao Paulo, junto ao Departamento de Tecnologia Rural da ESALQ.

**** Instituto Brasileiro do Café - Såo Paulo. 
sando a qualidade da bebida de diversas regiões do Brasil, não encontraram diferenças no teor de sólidos solúveis embora as diferenças na qualidade da bebida tivessem sido significativamente diferentes.

Na Guatemala, MENCHU (1966) encontrou correlação positiva entre etéreo e quantidade de fibra bruta com a qualidade da bebida; quanto maior a quantidade de extrato etéreo e menor a quantidade de fibra bruta, melhor era o café. Mais tarde, MENCHU \& IBARRA (1967), analisando cafés de várias regiões, não encontraram a mesma correlação.

AMORIM \& SILVA (1968) encontraram uma correlação positiva entre a qualidade da bebida e a atividade enzimática do polifenoloxidase. Os autores acharam que os melhores cafés possuiam uma atividade relativamente maior. SANINT \& VALENCIA (1970) trabalhando na Colômbia observaram que em cafés despolpados a atividade da polifenoxidase era maior nos melhores cafés.

Vários autores estudaram a composição química do café, sem relacioná-la com o tipo da bebida. TANGO (1971) apresentou uma revisão sobre a utilização do café e seus sub-produtos, na qual são citadas a composição de cafés de diversas variedades.

O objetivo do presente trabalho é o de determinar o teor de extrato etéreo e propriedades da fração lipídica e procurando relacioná-la com o tipo da bebida.

\section{MATERIAL E MÉTODOS}

O material constituiu-se de 104 amostras de 500 gramas de Coffea arabica L. var. Mundo Novo que foram coletadas pelo Instituto Brasileiro do Café (SERAC/SPl) nas mais diversas cafeeiras do Estado de São Paulo. Todas as amostras eram de café de terreiro e pertenciam à safra 71/72. Dentre essas amostras, as quarenta que apresentavam bebidas mais características foram selecionadas segundo a qualidade da bebida como segue: 10 como MOLE, 10 como DURA, 10 como RIADA e 10 como RIO.

Essas 40 amostras foram submetidas novamente à prova de degustação e analisadas estatisticamente. Apenas 28 amostras foram classificada com segurança, das quais, apenas 24 foram utilizadas (6 de cada tipo).

As amostras foram finamente trituradas em moinho (Pulverizador Mil) até 35-48 "MESH" (0,297 a $0,420 \mathrm{~mm})$ e em seguida analisadas.

O extrato etéreo foi determinado segundo método da A.O.A.C (1970). $O$ índice de acidez foi determinado segundo técnica descrita pelo INSTITUTO ADOLFO LUTZ (1951). Os índices de iôdo e de saponificação foram determinados segundo métodos descritos em JACOBS (1958).

A cromatografia em fase gasosa foi utilizada para determinação dos ácidos graxos, tendo sido esterificados segundo técnica descrita por LUDDY et al. (1960). As condições da análise cromatográfica foram as seguintes: 
- cromatógrafo CG-15, com detetor de ionização de chama.

- colunas gêmeas de 2 metros de comprimento com diâmetro interno de $3 / 16$ ", com fase estacionária Dietileno Glicol Succinato a $18 \%$ sobre Gas Chrom P A/W DMCS.

- temperatura da coluna: $180^{\circ} \mathrm{C}$.

- temperaturad o vaporizador: $220^{\circ} \mathrm{C}$.

- temperatura do detetor: $240^{\circ} \mathrm{C}$.

- gás de arraste: nitrogênio com fluxo de $50 \mathrm{ml} / \mathrm{min}$.

A identificação dos ácidos graxos foi feita por intermédio de padrões de ácidos graxos puros e através da distância de retenção (HAKEN, 1966).

Para análise estatística foi utilizado o delineamento inteiramente casualizado (PIMENTEL GOMES, 1970) com 4 tipos de bebidas e 6 repetições, no seguinte esquema:

\begin{tabular}{lc}
\hline causas de variação & graus de liberdade \\
\hline & \\
tratamentos & 3 \\
resíduo & 20 \\
total & 23 \\
\hline
\end{tabular}

Os testes F e Tukey foram utilizados e foi adotado o nível de $5 \%$ de probabilidade.

\section{RESULTADOS E DISCUSSÃO}

Os resultados obtidos são os apresentados nos QUADROS de n. ${ }^{\text {os }} 1$ a 14. 
QUADRO 1: Extrato etéreo de grãos de café verde, para cada tipo de bebida expresso em porcentagem de material seco (cada valor representa a média de 3 determinações).

\begin{tabular}{lllll}
\hline & \multicolumn{4}{c}{ TIPOS DE BEBIDAS } \\
\cline { 2 - 5 } Repetições & Mole & Duro & Riado & Rio \\
\hline 1 & 17,38 & 15,21 & 18,42 & 16,21 \\
2 & 17,90 & 15,08 & 15,59 & 17,30 \\
3 & 16,32 & 16,52 & 14,81 & 16,39 \\
4 & 15,90 & 14,68 & 16,45 & 15,85 \\
5 & 17,06 & 14,34 & 15,65 & 16,34 \\
6 & 17,44 & 16,20 & 15,35 & 16,55 \\
\hline Médias & 17,00 & 15,33 & 16,04 & 16,44 \\
\hline
\end{tabular}

C.V. : $5,49 \%$

d.m.s. $5 \%: 1,44$

QUADRO 2. Indice de iôdo do óleo de grãos de café verde, em cada tipo de bebida, expresso em gramas de iôdo por $100 \mathrm{~g}$ de óleo (cada valor representa a média de 3 determinações).

\begin{tabular}{lcrrr}
\hline & \multicolumn{4}{c}{ TIPOS DE } \\
\cline { 2 - 5 } Repetições & Mole & Duro & Riado & Rio \\
\hline \multirow{2}{*}{1} & 96,3 & 97,0 & 99,1 & 98,4 \\
2 & 97,9 & 101,5 & 96,9 & 99,8 \\
3 & 99,8 & 100,2 & 98,9 & 99,6 \\
4 & 98,5 & 99,8 & 101,0 & 98,4 \\
5 & 97,1 & 95,4 & 95,9 & 98,0 \\
6 & 98,0 & 97,6 & 95,4 & 99,0 \\
\hline Médias & 97,9 & 98,5 & 97,8 & 98,8 \\
\hline
\end{tabular}

C.V.: $1,75 \%$

d.m.s. $5 \%: 2,78$ 
QUADRO 3. Indice de saponificação do óleo de grãos de café verde, em cada tipo de bebida expresso em $\mathrm{mg}$ de KOH por $\mathrm{g}$ de óleo (cada valor representa a média de 3 determinações).

\begin{tabular}{lllll}
\hline & \multicolumn{4}{c}{ TIPOS DE } \\
\cline { 2 - 5 } Repetições & Mole & Duro & Riado & Rio \\
\hline 1 & 172,3 & 179,0 & 178,4 & 189,3 \\
2 & 178,6 & 178,5 & 178,2 & 188,3 \\
3 & 180,2 & 175,3 & 180,4 & 175,1 \\
4 & 181,5 & 179,3 & 182,6 & 184,3 \\
5 & 184,3 & 180,2 & 180,8 & 181,7 \\
6 & 177,9 & 180,0 & 178,9 & 173,6 \\
\hline Médias & 179,1 & 178,7 & 179,9 & 182,0 \\
\hline
\end{tabular}

C.V.: $2,83 \%$

d.m.s. $5 \%: 8,23$

QUADRO 4. Indice de acidez do óleo de grãos de café verde, em cada tipo de bebida expresso em mg de KOF por $\mathrm{g}$ de óleo (cada valor representa a média de 3 determinações).

\begin{tabular}{lcccr}
\hline & \multicolumn{4}{c}{ TIPOS DE } \\
\cline { 2 - 5 } Repetições & Mole & Duro & Riado & Rio \\
\hline 1 & 1,73 & 2,60 & 2,93 & 1,63 \\
2 & 3,73 & 4,04 & 3,45 & 4,83 \\
3 & 3,53 & 2,57 & 3,55 & 2,26 \\
4 & 2,53 & 3,04 & 3,47 & 2,43 \\
5 & 4,66 & 3,73 & 3,74 & 2,06 \\
6 & 1,80 & 5,01 & 5,34 & 2,03 \\
\hline Médias & 2,99 & 3,49 & 3,74 & 2,54 \\
\hline
\end{tabular}

C.V.: $32,62 \%$

d.m.s. $5 \%: 1,68$ 
QUADRO 5. Acido mirístico presente no óleo de grãos de café verde, em cada tipo de bebida expresso em $\%$ em peso do total de ácidos graxos (cada valor representa a média de 2 determinações).

\begin{tabular}{lcccc}
\hline & \multicolumn{4}{c}{ TIPOS DE } \\
\cline { 2 - 5 } Repetições & Mole & Duro & Riado & Rio \\
\hline 1 & 0,16 & 0,15 & 0,10 & 0,12 \\
2 & 0,10 & 0,10 & 0,13 & 0,09 \\
3 & 0,15 & 0,12 & 0,17 & 0,14 \\
4 & 0,11 & 0,13 & 0,14 & 0,17 \\
5 & 0,14 & 0,10 & 0,18 & 0,15 \\
6 & 0,11 & 0,10 & 0,15 & 0,12 \\
\hline Médias & 0,13 & 0,12 & 0,14 & 0,13 \\
\hline
\end{tabular}

C.V.: $19,77 \%$

d.m.s. $5 \%: 0,04$

QUADRO 6. Acido palmítico presente no óleo de grãos de café verde, em cada tipo de bebida expresso em \% em peso do total de ácidos graxos (cada valor representa a média de 2 determinações).

\begin{tabular}{lllll}
\hline & \multicolumn{4}{c}{ TIPOS DE } \\
\cline { 2 - 5 } Repetições & Mole & Duro & Riado & Rio \\
\hline 1 & 26,94 & 31,45 & 25,58 & 27,10 \\
2 & 22,43 & 23,97 & 23,58 & 26,64 \\
3 & 24,93 & 24,84 & 27,26 & 24,55 \\
4 & 22,79 & 26,34 & 26,76 & 21,10 \\
5 & 25,18 & 23,47 & 24,81 & 23,90 \\
6 & 24,90 & 24,84 & 23,99 & 26,03 \\
\hline Médias & 24,52 & 25,81 & 25,33 & 24,88 \\
\hline
\end{tabular}

C.V.: $8,55 \%$

d.m.s. $5 \%: 3,48$ 
QUADRO 7. Acido esteárico presente no óleo de grãos de café verde, em cada tipo de bebida expresso em \% em peso do total de ácidos graxos, em cada tipo de bebida (cada valor representa a média de 2 determinações).

\begin{tabular}{llllr}
\hline & \multicolumn{4}{c}{ TIPOS DE BEBIDAS } \\
\cline { 2 - 5 } Repetições & Mole & Duro & Riado & Rio \\
\hline 1 & 12,14 & 10,70 & 10,25 & 12,04 \\
2 & 11,79 & 12,89 & 11,66 & 12,24 \\
3 & 11,23 & 10,68 & 10,47 & 11,60 \\
4 & 12,21 & 11,70 & 10,48 & 14,35 \\
5 & 11,71 & 12,10 & 11,10 & 12,67 \\
6 & 11,56 & 16,76 & 11,51 & 9,77 \\
\hline Médias & 11,77 & 12,47 & 10,91 & 12,11 \\
\hline
\end{tabular}
C.V. $=11,55 \%$
d.m.s. $5 \%=2,20$

QUADRO 8. Acido araquídico presente no óleo de grãos de café verde, em cada tipo de bebida expresso em \% em peso do total de ácidos graxos (cada valor representa a média de 2 determinações).

\begin{tabular}{lcccc}
\hline & \multicolumn{4}{c}{ TIPOS DE } \\
\cline { 2 - 5 } Repetições & Mole & Duro & Riado & Rio \\
\hline 1 & 4,43 & 5,14 & 5,06 & 5,04 \\
2 & 4,97 & 5,52 & 4,80 & 5,02 \\
3 & 4,75 & 4,77 & 4,82 & 4,50 \\
4 & 5,60 & 5,17 & 5,89 & 6,47 \\
5 & 5,50 & 5,34 & 4,95 & 4,72 \\
6 & 4,70 & 5,47 & 5,19 & 5,75 \\
\hline Médias & 4,99 & 5,23 & 5,11 & 5,25 \\
\hline
\end{tabular}
C.V.: $9,69 \%$
d.m.s. $5 \%=0,80$ 
QUADRO 9. Acido behênico presente no óleo de grãos de café verde, em cada tipo de bebida expresso em \% em peso do total de ácidos graxos (cada valor representa a média de 2 determinações).

\begin{tabular}{lcccc}
\hline & \multicolumn{4}{c}{ TIPOS DE } \\
\cline { 2 - 5 } Repetições & Mole & Duro & Riado & Rio \\
\hline 1 & 1,06 & 0,97 & 1,22 & 1,06 \\
2 & 0,90 & 1,14 & 0,88 & 0,95 \\
3 & 1,32 & 1,23 & 1,30 & 1,16 \\
4 & 0,93 & 1,35 & 1,20 & 1,12 \\
5 & 1,27 & 0,88 & 0,92 & 1,12 \\
6 & 1,33 & 1,00 & 1,20 & 0,90 \\
\hline Médias & 1,13 & 1,09 & 1,12 & 1,05 \\
\hline
\end{tabular}

C.V. $=15,15 \%$

d.m.s. $5 \%=0,27$

QUADRO 10. Acido palmitolêico presente no óleo de grãos de café verde, em cada tipo de bebida expresso em $\%$ em peso do total de ácidos graxos (cada valor representa a média de 2 determinações).

\begin{tabular}{lcccc}
\hline & \multicolumn{4}{c}{ TIPOS DE BEBIDAS } \\
\cline { 2 - 5 } Repetiçбes & Mole & Duro & Riado & Rio \\
\hline $\mathbf{1}$ & 0,10 & 0,10 & 0,08 & 0,09 \\
$\mathbf{2}$ & 0,13 & 0,15 & 0,15 & 0,12 \\
3 & 0,29 & 0,13 & 0,14 & 0,11 \\
4 & 0,08 & 0,09 & 0,17 & 0,15 \\
5 & 0,14 & 0,15 & 0,10 & 0,10 \\
6 & 0,10 & 0,10 & 0,12 & 0,11 \\
\hline Médias & 0,14 & 0,12 & 0,13 & 0,11 \\
\hline
\end{tabular}

C.V. $=35,76 \%$

d.m.s. $5 \%=0,07$ 
QUADRO 11. Ácido olêico presente no óleo de grãos de café verde, em cada tipo de bebida expresso em $\%$ em peso do total de ácidos graxos (cada valor representa a média de 2 determinações).

\begin{tabular}{lllll}
\hline & \multicolumn{4}{c}{ TIPOS DE } \\
\cline { 2 - 5 } Repetições & Mole & Duro & Riado & Rio \\
\hline 1 & 13,19 & 11,40 & 11,31 & 13,67 \\
2 & 12,40 & 13,12 & 13,28 & 11,97 \\
3 & 13,30 & 11,67 & 10,33 & 12,33 \\
4 & 17,76 & 13,08 & 11,49 & 13,80 \\
5 & 13,10 & 11,90 & 13,07 & 13,72 \\
6 & 13,06 & 11,37 & 16,58 & 10,79 \\
\hline Médias & 13,80 & 12,09 & 12,67 & 12,71 \\
\hline
\end{tabular}
C.V. $=12,89 \%$
d.m.s. $5 \%=2,67$

QUADRO 12. Acido linolêico presente no óleo de grãos de café verde, em cada tipo de bebida expresso em $\%$ em peso do total de ácidos graxos (cada valor representa a média de 2 determinações).

\begin{tabular}{lllll}
\hline & \multicolumn{4}{c}{ TIPOS DE } \\
\cline { 2 - 5 } Repetições & Mole & Duro & Riado & Rio \\
\hline 1 & 39,77 & 37,41 & 43,29 & $\mathbf{3 7 , 7 3}$ \\
2 & 43,77 & 41,72 & 41,98 & 40,12 \\
3 & 41,63 & 43,03 & 42,48 & 38,27 \\
4 & 36,94 & 40,72 & 40,83 & 39,02 \\
5 & 39,02 & 39,06 & 42,01 & 41,45 \\
6 & 41,19 & 41,70 & 37,85 & 44,16 \\
\hline Médias & 40,38 & 40,60 & 41,40 & 40,12 \\
\hline
\end{tabular}

C.V. $=5,38 \%$

d.m.s. $5 \%=3,53$ 
QUADRO 13. Acido linolênico presente no óleo de grãos de café verde, em cada tipo de bebida expresso em $\%$ em peso do total de ácidos graxos (cada valor representa a média de 2 determinações).

\begin{tabular}{lcccc}
\hline & \multicolumn{4}{c}{ TIPOS DE BEBIDAS } \\
\cline { 2 - 5 } Repetições & Mole & Duro & Riado & Rio \\
\hline 1 & 2,38 & 1,78 & 2,72 & 3,11 \\
2 & 2,87 & 2,44 & 2,82 & 2,42 \\
3 & 2,75 & 2,90 & 2,72 & 2,64 \\
4 & 2,82 & 2,72 & 3,18 & 3,27 \\
5 & 3,07 & 3,35 & 3,40 & 1,99 \\
6 & 2,71 & 2,67 & 2,75 & 2,31 \\
\hline Média & 2,76 & 2,64 & 2,93 & 2,62
\end{tabular}

C.V. $=14,67 \% \quad$ d.m.s. $5 \%=0,65$

QUADRO 14. Composição média em ácidos graxos do óleo de grãos de café verde, variedade Mundo Novo, expresso em $\%$ em peso do total de ácidos graxos (cada valor representa a média de 24 determinações).

\begin{tabular}{lrr}
\cline { 2 - 3 } Ácido Graxo (1) & Média & \multicolumn{1}{c}{ Limites } \\
\hline $14: 0$ & 0,13 & $0,09-0,17$ \\
$16: 0$ & 25,14 & $21,67-28,61$ \\
$18: 0$ & 11,81 & $9,61-14,01$ \\
$20: 0$ & 5,14 & $4,34-5,94$ \\
$22: 0$ & 1,10 & $0,93-1,37$ \\
Total saturados & 43,32 & \\
$16: 1$ & 0,12 & $0,05-0,19$ \\
$18: 1$ & 12,82 & $10,15-15,49$ \\
$18: 2$ & 40,63 & $37,10-44,16$ \\
$18: 3$ & 2,74 & $2,09-3,39$ \\
Total insaturados & 56,31 & \\
\hline
\end{tabular}

(1) número de átomos de carbono : número de duplas ligações 
QUADRO 15. Valores de $F$ encontrados na Análise de Variância para os diversos indices e componentes.

\begin{tabular}{lc}
\hline Tratamentos & F \\
\hline Extrato etéreo & $4,38^{*}$ \\
Indice de iôdo & $0,49 \mathrm{n} . \mathrm{s}$. \\
Indice de acidez & $1,60 \mathrm{n} . \mathrm{s}$. \\
Indice de saponificação & $0,51 \mathrm{n} . \mathrm{s}$. \\
Ácido mirístico & $1,18 \mathrm{n} . \mathrm{s}$. \\
Ácido palmítico & $0,40 \mathrm{n} . \mathrm{s}$. \\
Âcido esteárico & $1,44 \mathrm{n} . \mathrm{s}$. \\
Ácido araquídico & $0,35 \mathrm{n} . \mathrm{s}$. \\
Acido behênico & $0,29 \mathrm{n} . \mathrm{s}$. \\
Ácido palmitolêico & $0,40 \mathrm{n} . \mathrm{s}$. \\
Âcido olêico & $1,12 \mathrm{n} . \mathrm{s}$. \\
Ácido linolêico & $0,38 \mathrm{n} . \mathrm{s}$. \\
Ácido linolênico & $0,75 \mathrm{n} . \mathrm{s}$. \\
\hline
\end{tabular}

*significativo a $\mathrm{p}<0,05$

Observando os resultados para extrato etéreo, QUADRO 1, e a correspondente análise estatística verificamos que 0 teste $F$ foi significativo, tendo o café de melhor qualidade apresentado maior teor de óleo, sendo diferente significativamente apenas do tipo DỤRO. Todavia não houveram diferenças estatísticas entre os tipos DURO, RIADO e RIO. MENCHU (1966) também encontrou correlação positiva entre o extrato etéreo e a qualidade da bebida, tendo os melhores cafés apresentado um teor maior de extrato etéreo. Os teores de extrato etéreo por nós obtido são um pouco mais altos do que os obtidos por TANGO \& CARVALHO (1963) para a mesma variedade (Mundo Novo).

Este teor, contudo não possibilita uma caracterização completa dos tipos de bebidas e assim sendo não podemos utilizar na classificação das bebidas.

Nos QUADROS de números 2 a 4 estão os valores dos índices de iôdo, de saponificação e acidez. Não foram detectadas diferenças significativas em função do tipo de bebida, sendo que o coeficiente de variação para índice de acidez foi muito alto $(32,62 \%)$, fato este que poderia explicar o valor de $\mathbf{F}$ não significativo.

Pelos QUADROS de números 5 a 13 com os valores para ácidos graxos de óleo de café extraido de grãos verdes de quatro tipos de bebidas, verificamos que o teste $F$ não apresentou diferença significativa para nenhum dos ácidos graxos, e que, portanto também não é possível caracterizar o tipo de bebida pela composição em ácidos graxos dos óleos de café. 
Os teores de ácidos palmítico e esteárico são próximos dos obtidos por KAUFMANN \& HAMSAGAR (1962) e por ECKEY (1964). Contudo são relativamente inferiores aos citados por HARTMANN et al. (1968) e TANGO (1971). Os teores de ácido linolêico estão de acordo com os citados por KAUFMANN \& HAMSAGAR (1962) e HARTMANN et al. (1968).

Observamos no QUADRO 14 os valores médios para composição em ácidos graxos e os limites de variação encontrados. Esses valores representam a composição média para a variedade Mundo Novo, e foram obtidos com os resultados dos quatro tipos de bebidas, pois não foram encontradas diferenças significativas entre os tipos de bebidas. Os ácidos graxos detectados foram os seguintes: mirístico, palmítico, esteárico, araquídico, behênico, palmitolêico, olêico, linalêico e linolênico, com prodominância de linolênico, palmític, olêico e esteárico.

No QUADRO 15 os valores de $\mathrm{F}$ obtidos na análise de variância para os diversos índices e componentes.

\section{CONCLUSÓES}

Pelos resultados obtidos nas análises química e estatística, pode-se tirar as seguintes conclusões:

1. Os índices de iôdo, de acidez e de saponificação não se mostraram eficientes para a classificação química de bebidas de café.

2. A composição em ácidos graxos confirma a conclusão $n .^{0} 1$, pois os resultados não diferiram significativamente para os quatro tipos de bebida.

3. O ácidos graxos detectados no óleo de café foram os seguintes: mirístico, palmitico esteárico, araquídico, behênico, palmitolêico, olêico, linolênico e minolêico.

4. O teor de extrato etéreo de café de bebida de boa qualidade de (MOLE) é mais alto do que a bebida DURA e não diferiu significativamente dos tipos RIADO e RIO. Portanto não é possível uma caracterização completa dos tipos de bebidas, por este valor.

\section{SUMMARY}

\section{"PROPERTIES AND COMPOSITION OF THE LIPID FRACTION IN GREEN COFFEE SAMPLES OF DIFFERENT KINDS OF BEVERAGE"}

The content and properties of the lipid fraction and fatty acid compositon of the oil in 28 samples of green coffee (Coffea arabica L., c. v. Mundo Novo) of four types of beverage, i.e., Soft, Hard, Rioy and Rio, were determined. The ether extract content was higher in coffees of better beverages, but significant difference was found only for Hard ones. It were not found differences in the fatty acid composition and in the chemical properties of 
the ether extract: saponification, iodine and acid numbers; none of them showed significance. It was concluded that these components and properties can not be used to characterize the type of beverage in green coffee. significance. It was concluded that these conmponents and properties can not be used to characterize the type of beverage in green coffee.

\section{LITERATURA CITADA}

AMORIM, H. V. \& D. M. SILVA, 1968 - Relação da atividade da polifenoloxidase do grão de Coffea arabica L. com a qualidade da bebida. Boletim Técnico Científico n. 31. ESALQ - USP, Piracicaba, São Paulo, Brasil. 16 pag.

A. O. A. C., 1970 - Official Methods of Analysis. $10^{\text {th }}$ ed. Washington D. C. ECKEY, E. W., 1964 - Vegetable Fats and Oils. Reinhold Publ. Co. New York. 1st ed. $760 \mathrm{pp}$.

GARRUTI, R. S., C. G. TEIXEIRA, O. Z. TOLEDO \& J. P. M. JORGE, $1962-$ Determinação de sólidos solúveis e qualidade da bebida em amostras de café dos portos brasileiros de exportação. Bragantia, 21 : 78-82.

HAKEN, J. K., 1966 - Retention time relationships in the gas chromatography of the methyl esters of fatty acids. J. Chromatog., $23: 375-381$.

HARTMANN, L., R. C. A. LAGO, J. S. TANGO, C. G. TEIXEIRA, $1968-0$ efeito da matéria insaponificável no comportamento do óleo do café. Boletim do Instituto de Tecnologia de Alimenttos (I. T. A. L.) 2 :61-71.

JACOBS, M. B., 1958 - «The Chemical Analysis of Food and Food Products». Van Nostrand-Reinhold. $3^{\text {rd }}$ ed. New York.

KRUG, H. P., 1940 - Cafés Duros. III. Relação entre percentagem de microorganismos e a qualidade do café. Revista do Instituto do Café (São Paulo), 2y: 1827-1831.

KAUFMAN, H. P. \& R. S. HAMSAGAR, 1962 - Component lipids of the coffee bean. I. Fatty acids esters of cafostol. Fette, Seifen Anstrichmittel, 64 : 206-213.

LUDDY, F. E., R. A. BARFORD \& R. A. RIEMENSCHNEIDER, 1960 - Direct conversion of lipid components to their methyl esters. J. Am. Oil Chem. Soc., $37: 447-451$.

MENCHU, J. F. E., 1966 - La determinación de la calidad del café. Boletim n.• 8. Association Nacional del Café. Guatemala. 51 pag.

MENCHU, J. F. E. \& E. IBARRA, 1967 - The chemical composition and the quality of Guatemala Coffee. pag. 144-154. A. S. I. C. Troisieme Colloque International sur la Chimie des Cafès Verts et Torréfiés et leurs derivés. Trieste. Italia.

PIMENTEL GOMES, F., 1970 - «Curso de Estatística Experimental» 4.^ ed. Livraria Nobel S/A. São Paulo.

SANINT, O. B. \& G. VALENCIA, 1970 - Actividad enzimatica en el grano de café en relación com la calidad de la bebida. I. Duracion de la fermentacion. Cenicafé (Colombia) $23: 59-71$.

TANGO, J. S. \& A. CARVAlho, 1963 - Teor de cafeína e óleo em variedades de café. Bragantia, 56 : 793-798.

TANGO, J. S., 1971 - Utilização industrial do café e dos seus sub-produtos. Boletim do Instituto de Tecnologia de Alimentos (I. T. A. L.) $28: 49-73$. 
